\title{
New corona virus and pregnancy; what should obstetricians know?
}

\author{
Ahmed A.A Taha ${ }^{1}$, Hatem A Awaga ${ }^{1}$, Marwa Z Elsayed ${ }^{2}$, Sara \\ $\mathrm{K}$ abdelaal ${ }^{2}$ and Salah R. Ahmed1 \\ ${ }^{1}$ Sohag University Hospital, Department of Obstetrics and Gynecology, \\ Sohag, Egypt. \\ ${ }^{2}$ Sohag University Hospital, Department of internal medicine, Sohag, \\ Egypt
}

\begin{abstract}
COVID-19 the disease caused by a new coronavirus has quickly raised the world concern by spreading globally at an accelerated rate and is considered now a pandemic, according to the World Health Organization. However, data regarding the situation of pregnant women with COVID-19 infection is still very scanty.

The pregnant women are considered a unique challenge during the COVID-19 pandemic and several questions about pregnant women and their newborns are not answered yet, whether they will develop distinct symptoms from non-pregnant patients and the ability of COVID-19 to spread vertically which may add more threats to the fetus and neonate. Previous studies have shown a higher fatality rate among pregnant women with SARS and MERS when compared with the available data regarding COVID-19 with pregnancy.

The aim of the current review is to highlight the vague points of COVID-19 infection during pregnancy, taking into consideration the clinical dilemma, diagnostic challenges and paying much attention to all adverse pregnancy outcomes such as intrauterine infection, maternal-fetal complications, and therapeutic controversies.

Keywords: COVID-19, pregnancy, maternal outcome, vertical transmissions, fetal outcome, therapeutic controversies.
\end{abstract}

\section{Introduction}

New coronavirus (COVID-19) is the world's most popular name and it is the focus of the interest of many scientists, researchers, politicians, and general people worldwide especially because of the surprisingly increasing burden of the disease (1).

Since December 2019, in Wuhan, China was the initial focus of a viral outbreak, rapidly many cases have been diagnosed in Italy, Iran, South Korea, Spain then globally $(2,3)$ and the WHO 11TH March 2020 announced the occurrence of a pandemic with the expected peak around April - May 2020 (4). Coronaviruses are viruses with various disease verities, ranging from flu-like symptoms to serious diseases, COVID19 disease caused by the novel coronavirus which is a new strain of enveloped RNA coronavirus $(1,5)$, "severe acute respiratory syndrome coronavirus 2" (SARS-CoV-2). Such strain was not previously reported in humans.

The high infectivity of the new strain is due to proven transmission of the virus between individuals through inhaling airborne droplets from symptomatic or asymptomatic persons who cough, sneeze, or touch contaminated surfaces $(6,7,8)$ and life-threatening consequences could have happened 
especially among the vulnerable group of patients with comorbidities (9).

During pregnancy, the maternal immune system is adapted to tolerate the growing fetus leaving the mother vulnerable to infections (10), which raises questions regarding the impact of COVID- 19 infection during pregnancy.

At present, very limited data is available regarding the epidemiology, clinical features, and treatment modalities of COVID-19 during pregnancy (11). Furthermore, little is known regarding the best mode of delivery, post-natal care, and the impact of breastfeeding.

The aim of the current review is to highlight the vague points of COVID19 infection during pregnancy, taking into consideration the clinical dilemma, diagnostic challenges and paying much attention to all adverse pregnancy outcomes such as intrauterine infection, maternal-fetal complications, and therapeutic controversies.

\section{Clinical dilemma and maternal outcomes}

COVID-19 disease is a universally spreading infectious disease affecting all age groups particularly those with lower immunity such as elderly people with associated comorbidities, However, the effect of COVID-19 on pregnant women is not well studied yet $(12,13)$, all data available in the literature are based on past reports of same family coronaviruses (SARS$\mathrm{CoV}$ and MERS-CoV) with a substantial risk of severe maternal and neonatal illness (14).

Pregnancy is a special situation characterized by physiological, anatomical, hormonal and immunological changes to maintain the growing allogenic fetus, however, such physiological changes render the mother more prone to severe infections (15), immunological changes include the alteration in cell-mediated immunity which increases the maternal vulnerability to intracellular organisms like viruses (16), in addition to the anatomical changes which decrease the maternal tolerance to hypoxia (17). Furthermore, estrogen-mediated upper respiratory congestion that affects half of the pregnant ladies in the late trimester and usually presents with rhinitis and mild upper respiratory tract infection. These symptoms may simulate the symptoms of COVID-19 infection (18), which adds more challenges on the way of diagnosis of COVID-19 during pregnancy.

Suspected pregnant women with COVID-19 infection are usually presented with clinical symptoms varying in severity from the common cold to severe respiratory illness and death, the clinical characteristics of overwhelming COVID-19 pregnant women were similar to infected nonpregnant women, common manifestations such as nausea, malaise, exhaustion, myalgia, dry cough and shortness of breath, others may present with nasal congestion, runny nose, sore throat, hemoptysis or diarrhea may be present. Infection of the respiratory tract may include mild pneumonia or severe pneumonia with marked respiratory distress (4, 5). Asymptomatic patients who were positive for the virus at admission (19) represent a significant commitment to illness spread and a major threat to health care providers (20). Early studies suggest that in $17-29 \%$ of hospitalized cases, the incidence of acute respiratory distress (ARDS) occurs at approximately $1 \%$.

The laboratory results of pregnant women with COVID-19 infection show normal white blood cells or even leucopenia at early stages, lymphopenia, and thrombocytopenia. While, liver enzymes, C-reactive 
protein, and creatine phosphokinase may be increased (21).

Chest computed tomography (CT) scans without contrast is a very useful imaging modality to confirm or rule out viral pneumonia and should be implemented in all suspected pregnant women with COVID-19 infection, radiologic signs revealed bilateral, multi-lobar ground-glass opacities or consolidation which show the underlying vessels $(21,22)$. Chest imaging may aid but not replace molecular confirmation of COVID-19. A recent study showed that chest CT sensitivity was greater in diagnosing COVID 19 than RT RCR 98\% vs $71 \%$. (25). Viral isolation is considered to be the gold standard to test COV 2 SARS using RT PCR 23, but the clinical problem is the false-negative detection of nuclear acid (23) and thus makes the imaging examination crucial. Also, hospital isolation practices may be extremely influenced by the strategy of universal testing and detecting Covid19 status (24).

\section{Fetal outcome}

Previous studies have shown that the risk of adverse neonatal results including accidental abortion, premature labor, and intrauterine growth retardation, and endotracheal intubation, admission to neonatal intensives, renal failure, and DIC are highly significant when the pregnant women become infected with SARS and MERS. (26).

However, the predicted neonatal outcomes of pregnant women with COVID19 infection were likely to be less severe than estimated for those with MERS-CoV or SARS $\mathrm{CoV}$ infection (27).

Despite the limited data available about the effects of COVID-19 on pregnancy, higher risk for preterm delivery was reported in $47 \%$ of cases (18), miscarriage in $2 \%$ and IUGR in $10 \%$ of cases, in addition to other obstetric complications such as preeclampsia, premature rupture of membranes, irregular uterine contractions and stillbirth, However, it is not evident that such outcomes were causally related to COVID-19 infection, and further studies are needed $(28,29)$. The risk of congenital abnormalities has not risen due to the mother's fever. (34). the theoretical risk of vertical transmission of COVID-19 in infected mothers is still concerned (32, 33) despite big evidence from literature against the probability of such a way of transmission $(28,29,30,31)$.

\section{Management of pregnant women with COVID-19}

The protocol of management of a pregnant woman with COVID-19 should be individualized according to disease severity and the trimester of their pregnancy (35), risk stratification of every case should be done and patients are classified into three degrees, either mild in which the patient is vitally stable or severe in which the respiration rate is $\geq 30 / \mathrm{min}$, resting $\mathrm{SaO} 2$ is $\leq 93 \%$ and arterial blood oxygen partial pressure $(\mathrm{PaO} 2) /$ oxygen concentration ( $\mathrm{FiO} 2)$ is $\leq 300$ $\mathrm{mmHg}$ or critical in which the patient is shocked with multi-organ failure, mechanical ventilation indicated in those with respiratory failure, severe hypoxia may require oxygenation through the extra-corporal membrane. Such categories are based on clinical evaluation (22), the early detection and intervention of pregnant cases with COVID-19 may improve pregnancy outcomes (28) by reducing the probability of obstetric complications such as pregnancy loss, fetal growth retardation, and preterm labor.

Regarding the use of anti-viral drugs for coronavirus during pregnancy, there is no worldwide consensus concerning any specific antiviral drugs 
for COVID-19 pneumonia and such treatment can be initiated during pregnancy, according to risk-benefit ratio to the fetus. A recent study recommends the use of lopinavir/ritonavir for such cases as safe with pregnancy. (22), similarly, corticosteroids are not generally recommended in COVID-19 pneumonia with pregnancy except in cases with ARDS, however, if it is required in cases of preterm labor to enhance fetal lung maturity, intramuscular betamethasone injections can be given.

According to available data, breastfeeding can be allowed in patients who are physically good and can tolerate breastfeeding; and who became noninfectious. The length of separation cannot be accurately estimated with the available knowledge and should be decided on an individual basis after a conversation between immunologists, infection control experts, and neonatologists (14). It is worth mention that mothers with known or suspected COVID-19 must be strict to standard and contact precautions during breastfeeding (21).

\section{Conclusion}

COVID-19 pandemic caused by the novel virus SARS-CoV-2 is a huge problem, threatening all the population groups especially pregnant ladies due to many physiological and immunological changes occurring during pregnancy that render pregnant women more vulnerable to respiratory pathogens and serious pneumonia than others. Their chance to catch COVID19 infection increases, especially, if they are suffering from other comorbidities.

Up till now, there is no much data regarding the prevalence and clinical features of COVID-19 during pregnancy, childbirth and the postnatal period, however, data from countries with a high number of cases refer to a very low probability of intrauterine transmission of the virus to the fetus from infected pregnant mother.

The physician should adhere to all currently available recommendations, as well as previous experiences from the prevention and control of SARS and MERS and more attempts must be made to protect both mothers and fetuses with the ongoing COVID-19 pandemic. Further studies should be done to cover the outcomes of the first and second trimester of pregnant women infected with COVID-19 and the role of more antiviral drugs in addition to the potential benefits of plasma extraction from the blood of patients who are cured of the virus. Furthermore, the impact of lactation on postnatal immunological development and the probability of neonatal infection should be further estimated.

\section{References}

1- Guan WJ, Ni ZY, Hu Y, Liang WH, Ou CQ, He JX, Liu L, Shan H, Lei CL, Hui DS, Du B. Clinical characteristics of 2019 novel coronavirus infection in China. MedRxiv. 2020 Jan 1.

2- WHO. Novel coronavirus-China. Jan 12, $2020 . \quad$ http://www.who. int/csr/don/12-january-2020-novelcoronavirus-china/en/ (accessed Jan 19, 2020).

3- WHO. Coronavirus disease 2019 (COVID-19) situation report 53. March 13 , 2020.

https://www.who.int/docs/defaultsource/ coronaviruse/situationreports/20200313-sitrep-53-covid19.pdf (accessed March 13, 2020).

4- Wu JT, Leung $\mathrm{K}$, Leung GM. Nowcasting and forecasting the potential domestic and international spread of the 2019-nCoV outbreak originating in Wuhan, China: a modelling study. The Lancet. 2020 Feb 29;395(10225):689-97.

5- Heymann DL, Shindo N. COVID-19: what is next for public health?. The 
Lancet. 2020 Feb 22;395(10224):5425.

6- Chan JF, Yuan S, Kok KH, To KK, Chu H, Yang J, Xing F, Liu J, Yip CC, Poon RW, Tsoi HW. A familial cluster of pneumonia associated with the 2019 novel coronavirus indicating person-toperson transmission: a study of a family cluster. The Lancet. $2020 \mathrm{Feb}$ 15;395(10223):514-23.

7- Li Q, Guan X, Wu P, Wang X, Zhou L, Tong Y, Ren R, Leung KS, Lau EH, Wong JY, Xing X. Early transmission dynamics in Wuhan, China, of novel coronavirus-infected pneumonia. New England Journal of Medicine. 2020 Jan 29.

8- Rothe C, Schunk M, Sothmann P, Bretzel G, Froeschl G, Wallrauch C, Zimmer $\mathrm{T}$, Thiel V, Janke C, Guggemos W, Seilmaier M. Transmission of 2019-nCoV infection from an asymptomatic contact in Germany. New England Journal of Medicine. 2020 Mar 5;382(10):970-1.

9- Wu Z, McGoogan JM. Characteristics of and important lessons from the coronavirus disease 2019 (COVID-19) outbreak in China: summary of a report of 72314 cases from the Chinese Center for Disease Control and Prevention. Jama. 2020 Apr 7;323(13):1239-42.

10- Fortner KB, Nieuwoudt C, Reeder CF, Swamy GK. Infections in Pregnancy and the Role of Vaccines. Obstetrics and Gynecology Clinics. 2018 Jun 1;45(2):369-88.

11- Chen H, Guo J, Wang C, Luo F, Yu X, Zhang W, Li J, Zhao D, Xu D, Gong Q, Liao J. Clinical characteristics and intrauterine vertical transmission potential of COVID-19 infection in nine pregnant women: a retrospective review of medical records. The Lancet. 2020 Mar 7;395(10226):809-15.

12- Favre G, Pomar L, Musso D, Baud D. 2019-nCoV epidemic: what about pregnancies? Lancet (London, England). $\quad 2020 \quad$ Feb 22;395(10224):e40.

13- Qiao J. What are the risks of COVID19 infection in pregnant women?. The Lancet. 2020 Mar 7;395(10226):760-2.
14- Rasmussen SA, Smulian JC, Lednicky JA, Wen TS, Jamieson DJ. Coronavirus Disease 2019 (COVID19) and Pregnancy: What obstetricians need to know. American journal of obstetrics and gynecology. 2020 Feb 24.

15- Goodnight WH, Soper DE. Pneumonia in pregnancy. Critical care medicine. 2005 Oct 1;33(10):S390-7.

16- Nelson-Piercy, C., 2015. Handbook of obstetric medicine. CRC press.

17- O'Day, M.P., 1997, August. Cardiorespiratory physiological adaptation of pregnancy. In Seminars in perinatology (Vol. 21, No. 4, pp. 268275). WB Saunders.

18- Dashraath P, Jeslyn WJ, Karen LM, Min LL, Sarah L, Biswas A, Choolani MA, Mattar C, Lin SL. Coronavirus disease 2019 (COVID-19) pandemic and pregnancy. American Journal of Obstetrics and Gynecology. 2020 Mar 23.

19- Breslin N, Baptiste C, Miller R, Fuchs K, Goffman D, GyamfiBannerman C, D'Alton M. COVID-19 in pregnancy: early lessons. American Journal of Obstetrics \& Gynecology MFM. 2020 Mar 27:100111.

20- Bai Y, Yao L, Wei T, Tian F, Jin DY, Chen L, Wang M. Presumed asymptomatic carrier transmission of COVID-19. Jama. 2020 Apr 14;323(14):1406-7.

21- Karimi-Zarchi M, Neamatzadeh $H$, Dastgheib SA, Abbasi H, Mirjalili SR, Behforouz A, Ferdosian F, Bahrami R. Vertical transmission of coronavirus disease 19 (COVID-19) from infected pregnant mothers to neonates: a review. Fetal and pediatric pathology. 2020 Apr 1:1-5.

22- Liang H, Acharya G. Novel corona virus disease (COVID-19) in pregnancy: What clinical recommendations to follow?. Acta Obstetricia et Gynecologica Scandinavica. 2020 Apr;99(4):439-42.

23- Tahamtan A, Ardebili A. Real-time RT-PCR in COVID-19 detection: issues affecting the results.

24- Sutton D, Fuchs K, D'alton M, Goffman D. Universal screening for SARS-CoV-2 in women admitted for 
delivery. New England Journal of Medicine. 2020 Apr 13.

25- Ai T, Yang Z, Hou H, Zhan C, Chen C, Lv W, Tao Q, Sun Z, Xia L. Correlation of chest CT and RT-PCR testing in coronavirus disease 2019 (COVID-19) in China: a report of 1014 cases. Radiology. 2020 Feb 26:200642.

26- Wong SF, Chow KM, Leung TN, Ng WF, Ng TK, Shek CC, Ng PC, Lam PW, Ho LC, To WW, Lai ST. Pregnancy and perinatal outcomes of women with severe acute respiratory syndrome. American journal of obstetrics and gynecology. $2004 \mathrm{Jul}$ 1;191(1):292-7.

27- Qiao J. What are the risks of COVID19 infection in pregnant women?. The Lancet. 2020 Mar 7;395(10226):760-2.

28- Chen H, Guo J, Wang C, Luo F, Yu X, Zhang W, Li J, Zhao D, Xu D, Gong Q, Liao J. Clinical characteristics and intrauterine vertical transmission potential of COVID-19 infection in nine pregnant women: a retrospective review of medical records. The Lancet. 2020 Mar 7;395(10226):809-15.

29- Zhu H, Wang L, Fang C, Peng S, Zhang L, Chang G. Clinical analysis of 10 neonates born to mothers with 2019nCoV pneumonia. Translational Pediatrics, 9 (1), 51-60.

30- Li Y, Zhao R, Zheng S, Chen X, Wang J, Sheng X, Zhou J, Cai H, Fang
Q, Yu F, Fan J. Early release-lack of vertical transmission of severe acute respiratory syndrome coronavirus 2, China.

31- Chen Y, Peng H, Wang L, Zhao Y, Zeng L, Gao H, Liu Y. Infants born to mothers with a new coronavirus (COVID-19). Frontiers in pediatrics. 2020 Mar 16;8:104.

32- Woodward A. A pregnant mother infected with the coronavirus gave birth, and her baby tested positive 30 hours later. Business insider, India [online]. 2020 Mar.

33- Murphy S. Newborn baby tests positive for coronavirus in London. The Guardian. 2020 Mar;14.

34- Gustavson K, Ask H, Ystrom E, Stoltenberg C, Lipkin WI, Suren P, Håberg SE, Magnus P, Knudsen GP, Eilertsen E, Bresnahan M. Maternal fever during pregnancy and offspring attention deficit hyperactivity disorder. Scientific reports. 2019 Jul 2;9(1):1-0.

35- Wang SS, Zhou X, Lin XG, Liu YY, Wu JL, Sharifu LM, Hu XL, Rong ZH, Liu W, Luo XP, Chen Z. Experience of Clinical Management for Pregnant Women and Newborns with Novel Coronavirus Pneumonia in Tongji Hospital, China. Current Medical Science. 2020 Mar 26:1-5. 